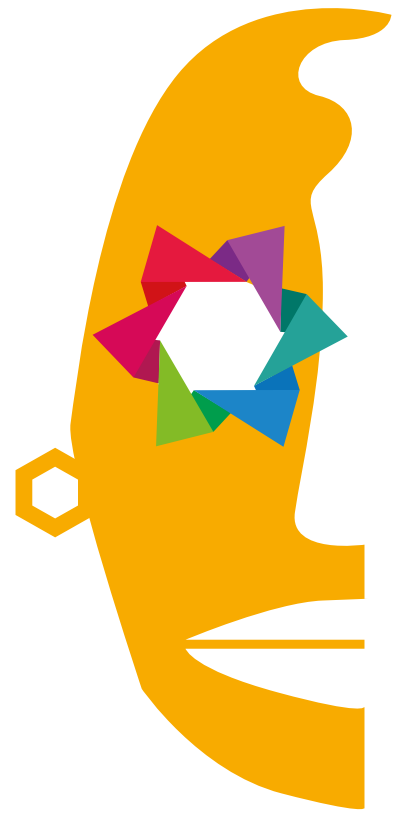

Alma Fernández

Tercero

Directora de Kandisky Galería

Costa Rica

\section{Galería en tributo al pintor costarricense Rafa Fernández (1935-2018)}

\section{Resumen}

El pintor Rafael Ángel Fernández Piedra, fallecido en 2018, es considerado uno de los artistas más representativos de Costa Rica, cuya obra ha tenido también una proyección internacional considerable, al formar parte de la Colección del Museo José Luis Cuevas en Ciudad de México, así como de la Colección del Museo Rally de Arte Contemporáneo, en Punta del Este, Uruguay, entre otros. Obtuvo el premio Aquileo J. Echeverría en Artes Plásticas en 1968, 1972 y 1975, así como el premio Nacional de Cultura Magón en 2002, el más importante galardón que otorga el Estado costarricense en reconocimiento a una vida dedicada a la cultura. Como homenaje póstumo a este insigne creador, en esta edición la Revista Ístmica convierte su sección de Artes Visuales en una galería virtual dedicada a la exposición de parte de su obra, comentada sentidamente por su hija, la curadora y también artista, Alma Fernández.

Palabras clave: Rafa Fernández, pintura, grabado, litografía, arte costarricense.

\begin{abstract}
The painter Rafael Ángel Fernández Piedra, who died in 2018, is considered one of the most representative artists of Costa Rica, whose work has also had a considerable international projection, as it forms part of the Collection of the José Luis Cuevas Museum in Mexico City, as well as as from the Collection of the Rally Museum of Contemporary Art, in Punta del Este, Uruguay, among others. He won the Aquileo J. Echeverría Prize in Plastic Arts in 1968, 1972 and 1975, as well as the National Magón Culture Prize in 2002, the most important award given by the Costa Rican State in recognition of a life dedicated to culture. As a posthumous tribute to this famous creator, in this edition the Ístmica Magazine turns his Visual Arts section into a virtual gallery dedicated to the exhibition of part of his work, commented heartily by his daughter, the curator and also artist, Alma Fernández.
\end{abstract}

Keywords: Rafa Fernández, painting, engraving, lithography, Costa Rican art. 
"Pinto, luego existo. Mientras pinto vivo, mientras vivo pinto, pintar y vivir son para mí lo mismo". Esa fue la premisa de mi padre, Rafa Fernández, a quien citaré libremente en este recorrido por su universo pictórico.

Figura 1. Autorretrato (Galería Uffiizi)

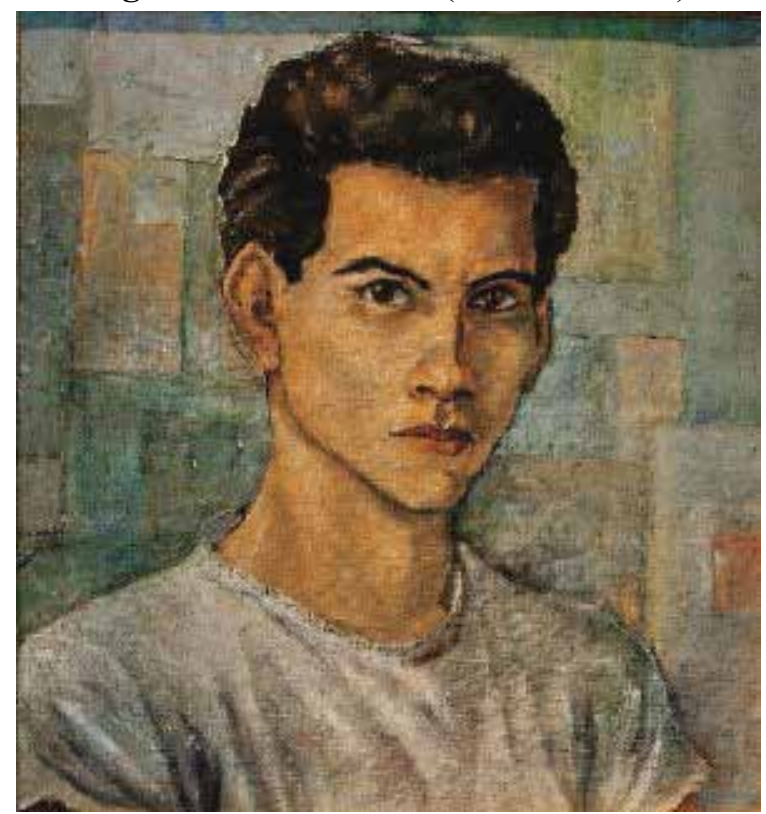

Fuente: Alma Fernández Tercero

No es posible resumir una vida tan intensa, $\tan$ rica y $\tan$ provechosa en un texto, pero puedo decir que mi padre fue un hombre brillante, de una mente clara, de una inteligencia extraordinaria, de una voluntad admirable que sabía lo que quería y como lograrlo. "Pinto con total desparpajo, dejándome ir, reencontrándome con personajes que alguna vez, -aunque sea en sueños-, me fueron propios". 
Figura 2. La fuga

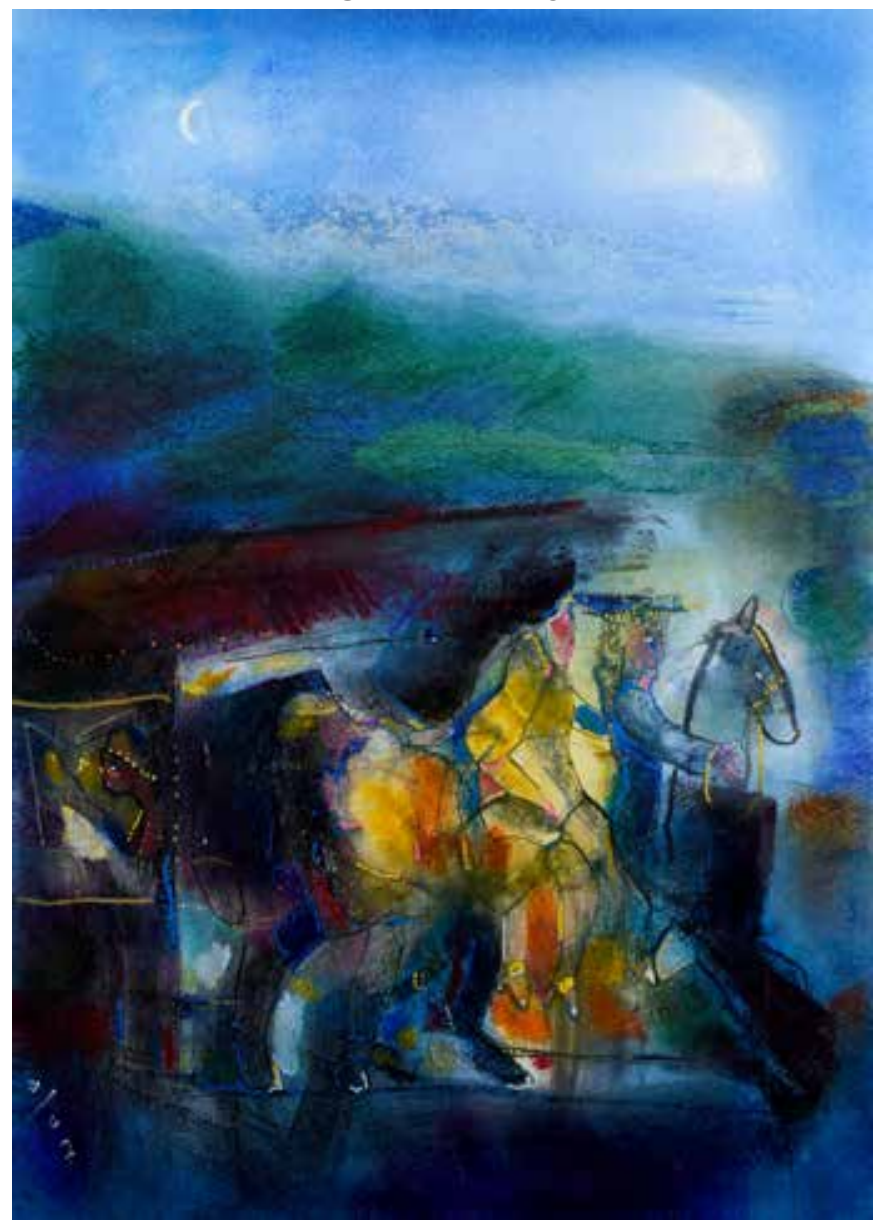

Fuente: Alma Fernández Tercero

Supo romper todas las ataduras, su genio le permitió superar la adversidad y logró crear un universo de magia y expresionismo con absoluta libertad. "Siento que se me acorta el tiempo y tengo mucho que decir todavía...". Él quería sacarlo todo, expresarlo en su pintura. No dejó nada inconcluso, no perdió un minuto, tenía la fuerza existencial para seguir pintando hasta morir decía, y así lo hizo.

La obra de mi padre lo define como un gran exponente del realismo mágico en Centroamérica y lo reconoce como un artista consagrado en el ámbito internacional. Lo respalda una carrera ininterrumpida de 65 años de la que dan fe la lista de museos internacionales que exhiben su obra y los importantes reconocimientos que recibió a lo largo de su carrera. La Gallería degli Uffizi, el Museo Goya para mencionar un par de instituciones y entre sus reconocimientos 3 premios 
nacionales Aquileo J. Echeverría y el premio Magón, que es el máximo reconocimiento otorgado por el Estado costarricense a un ciudadano destacado por la obra de toda una vida.

Mi padre vivió una época de grandes sucesos, épocas de guerra y de postguerra, vivió en Madrid en la época de Franco y luego volvió al Madrid del destape, una época de grandes cambios tecnológicos, de depresiones económicas y también de crecimiento, de hechos históricos que marcaron su tiempo y su obra y le dieron una visión global de su entorno, amaba la música, el teatro, la literatura y sobre todo la poesía, era un artista sin fronteras, sin fronteras físicas y sin fronteras mentales, fue un costarricense universal.

Figura 3. Sociedad de consumo

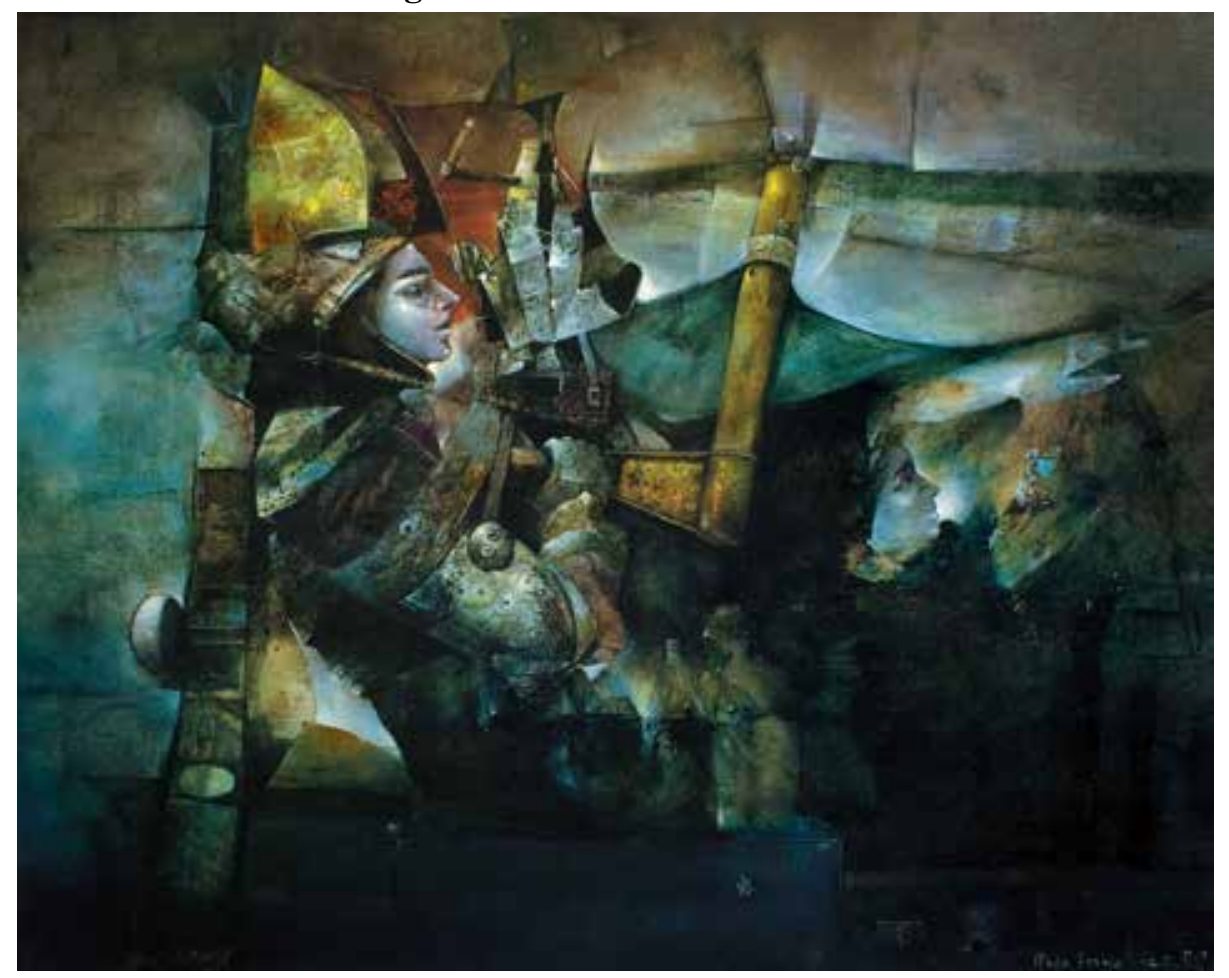

Fuente: Alma Fernández Tercero 
Figura 4. La guerra

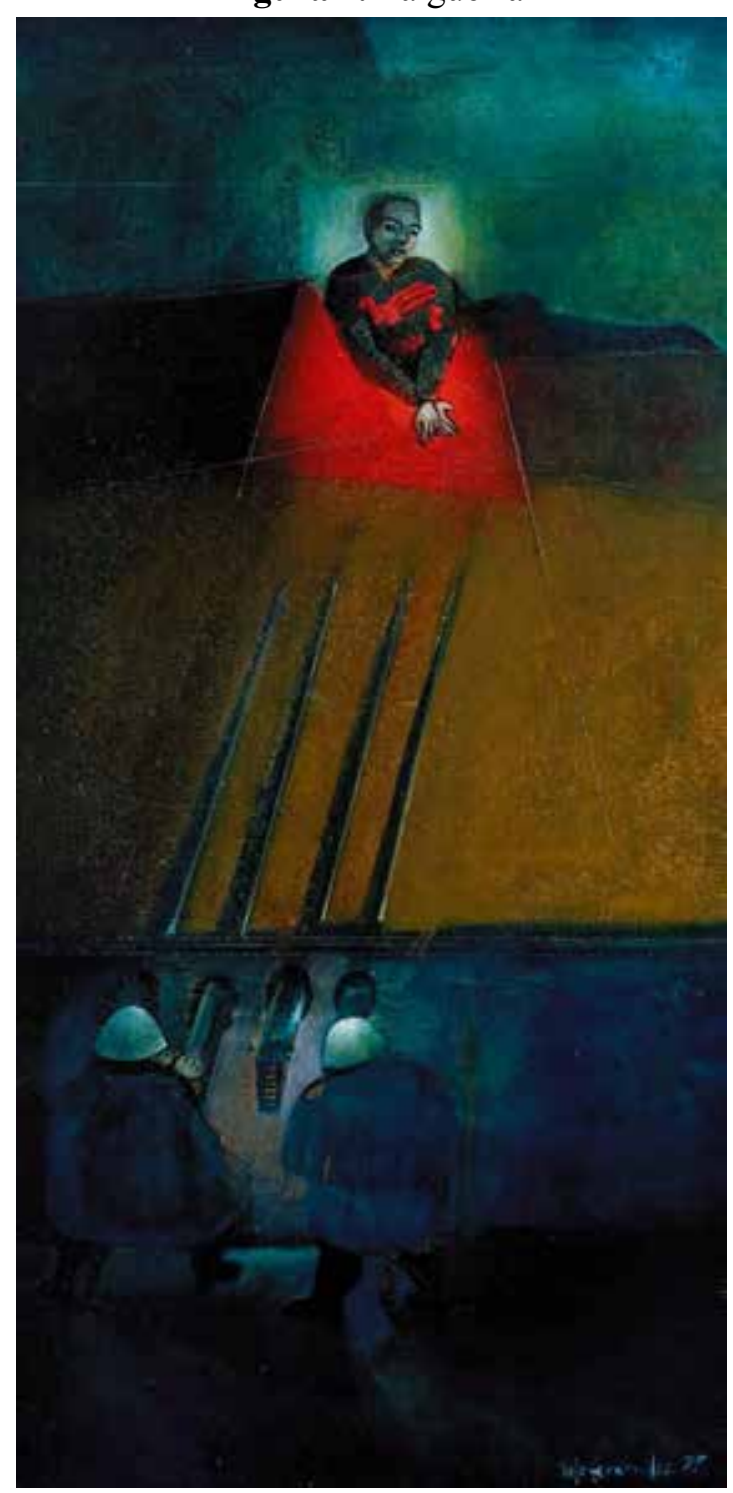

Fuente: Alma Fernández Tercero

Su carrera como pintor inició desde joven en La Casa del Artista, de donde gracias a una beca gestionada por la misma doña Olga Espinach pasa a la escuela de Bellas Artes de Managua bajo la dirección del Maestro Rodrigo Peñalba de quien hereda una tremenda carga expresionista y una atmósfera oscura, tanto técnica como temática, poblada por personajes monstruosos y grotescos que caracterizan los años' 60 . 
Figura 5. El Intelectual

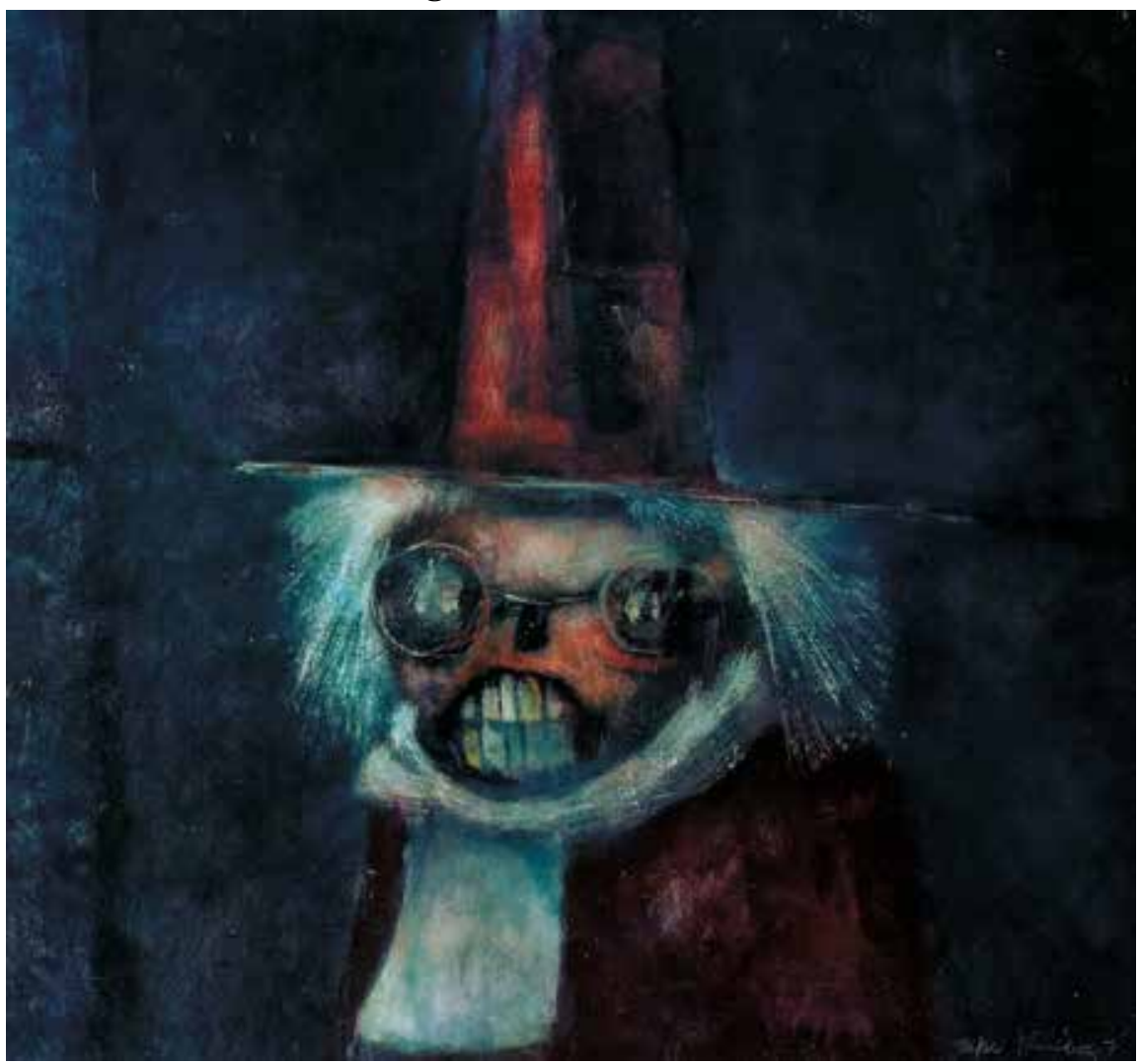

Fuente: Alma Fernández Tercero 
Galería en tributo al pintor costarricense Rafa Fernández (1935-2018)

Figura 6. La gula

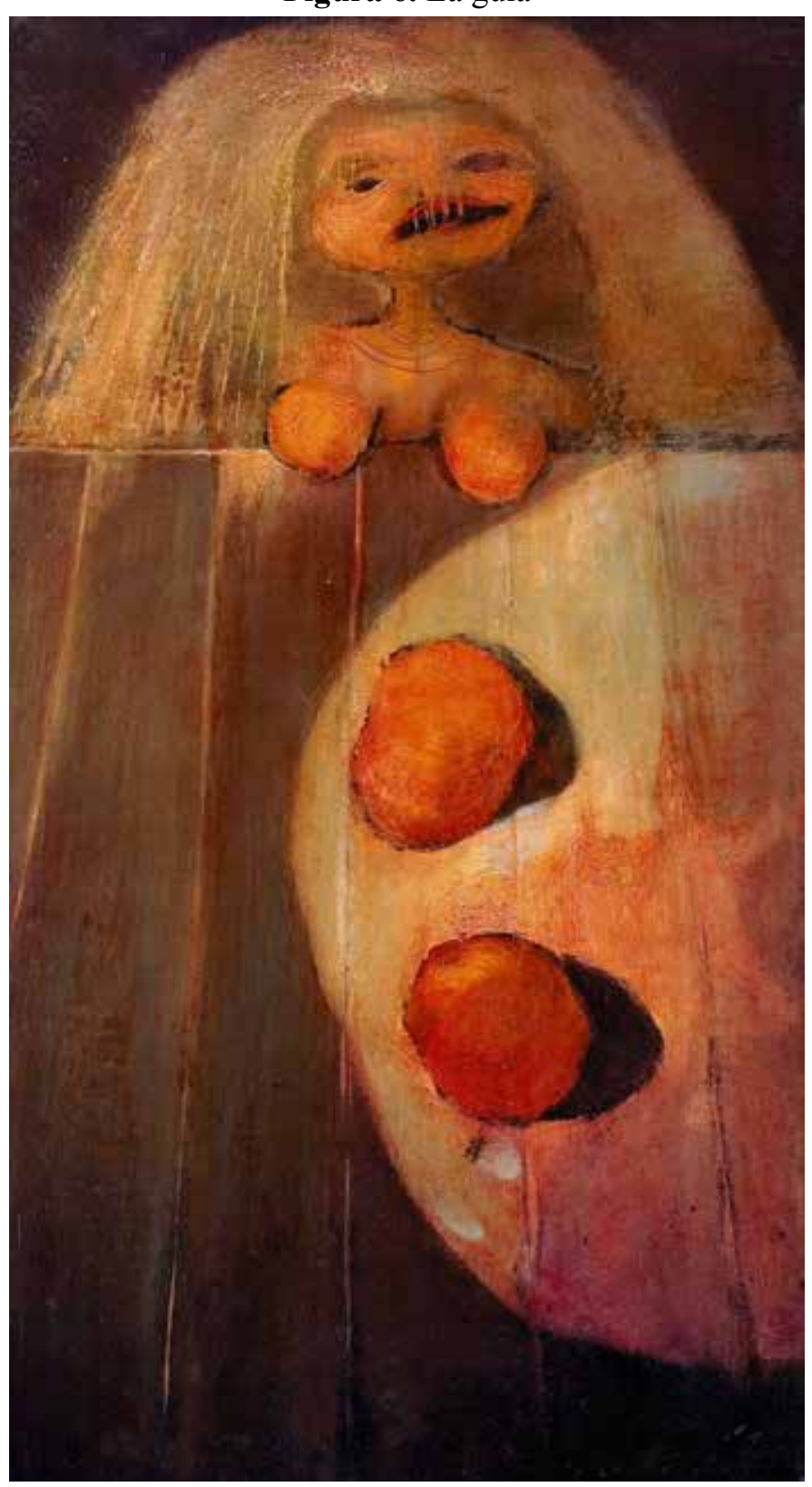

Fuente: Alma Fernández Tercero 
Figura 7. Retrato de familia

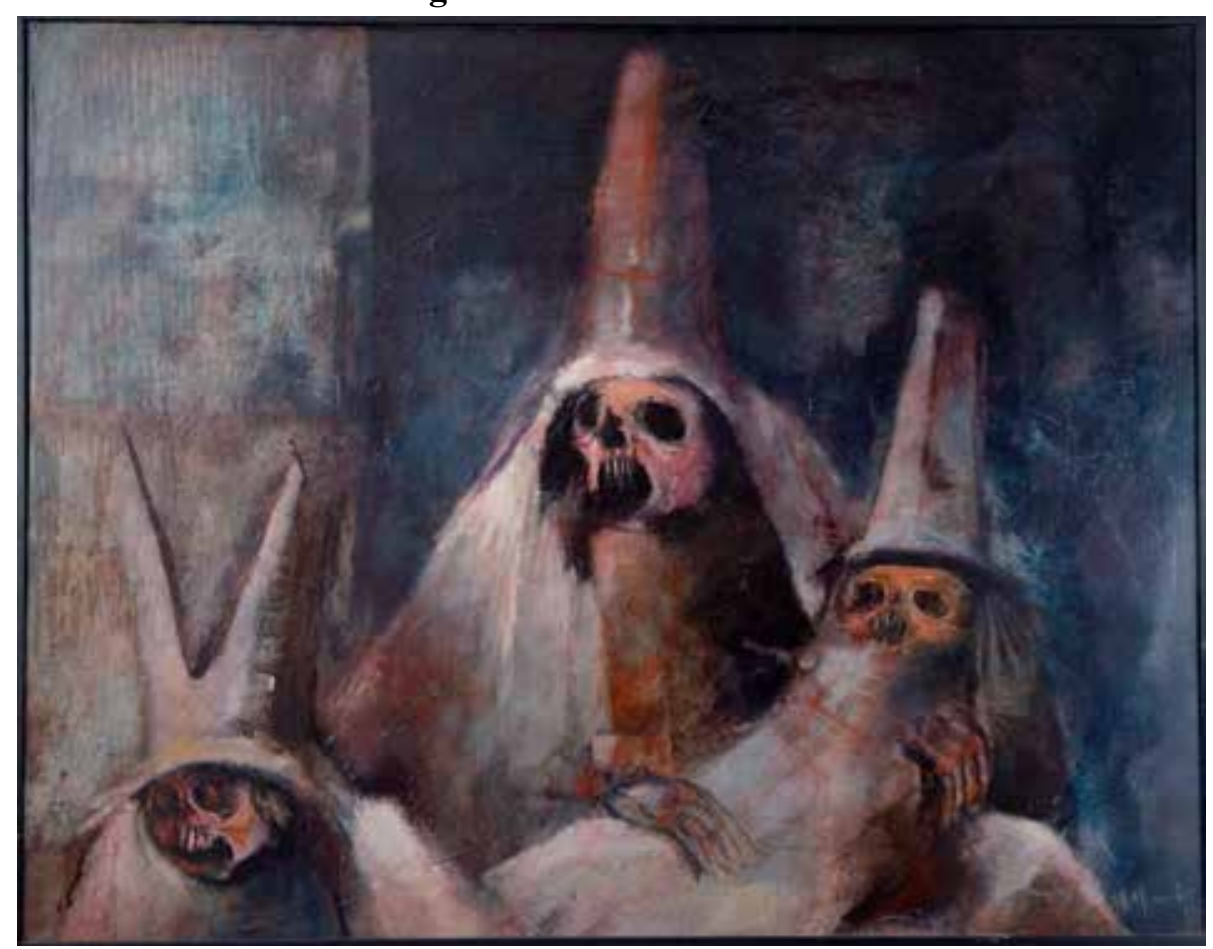

Fuente: Alma Fernández Tercero

Le sigue un período caracterizado por una atmósfera esotérica y teatral que abarca los intensos años '70, en los cuales se consolida como una joven promesa de las artes visuales que no defraudaría al maestro que había puesto su mirada en él, don Manuel de la Cruz González. 
Galería en tributo al pintor costarricense Rafa Fernández (1935-2018)

Figura 8. La visita del doctor

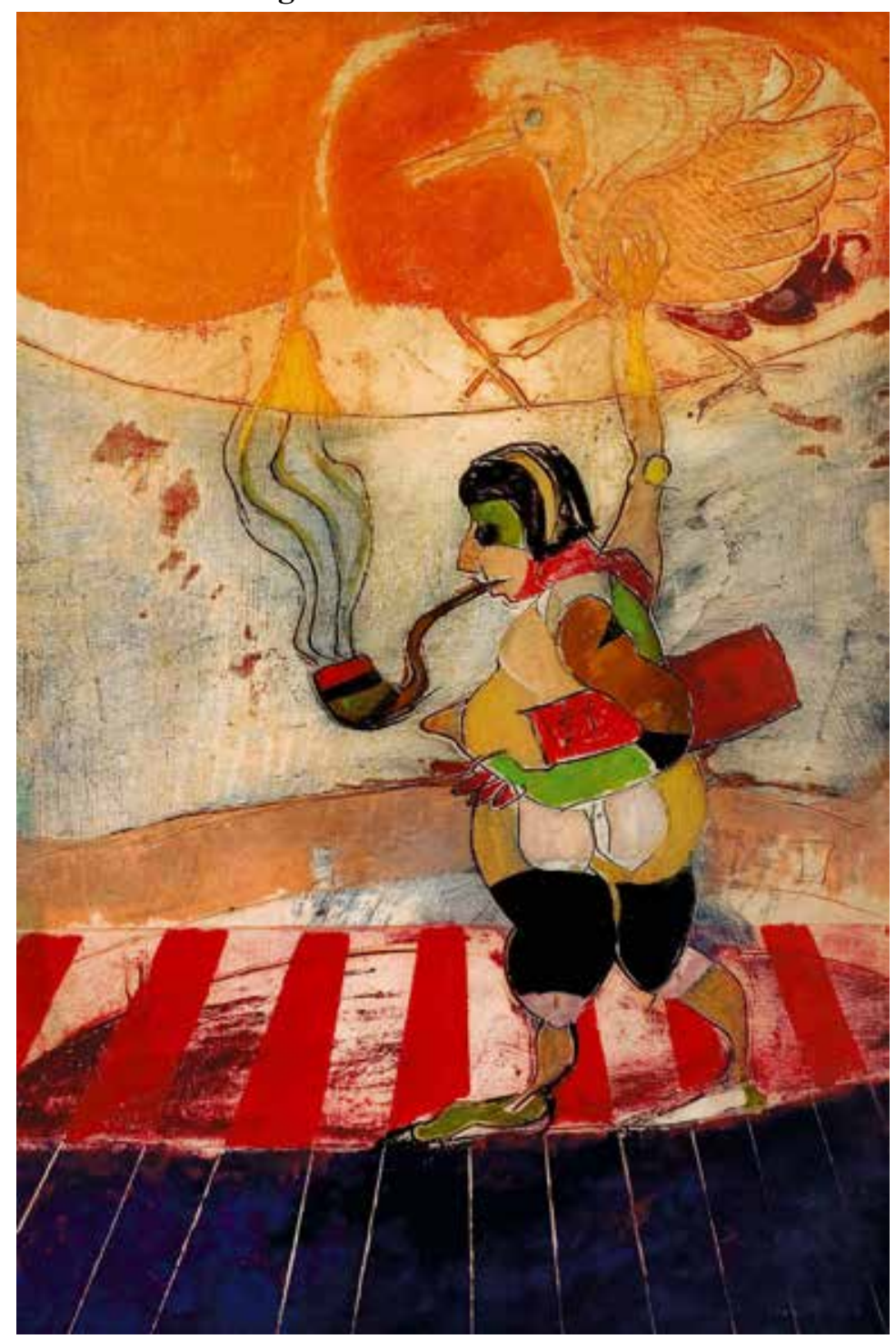

Fuente: Alma Fernández Tercero 
Figura 9. El circo

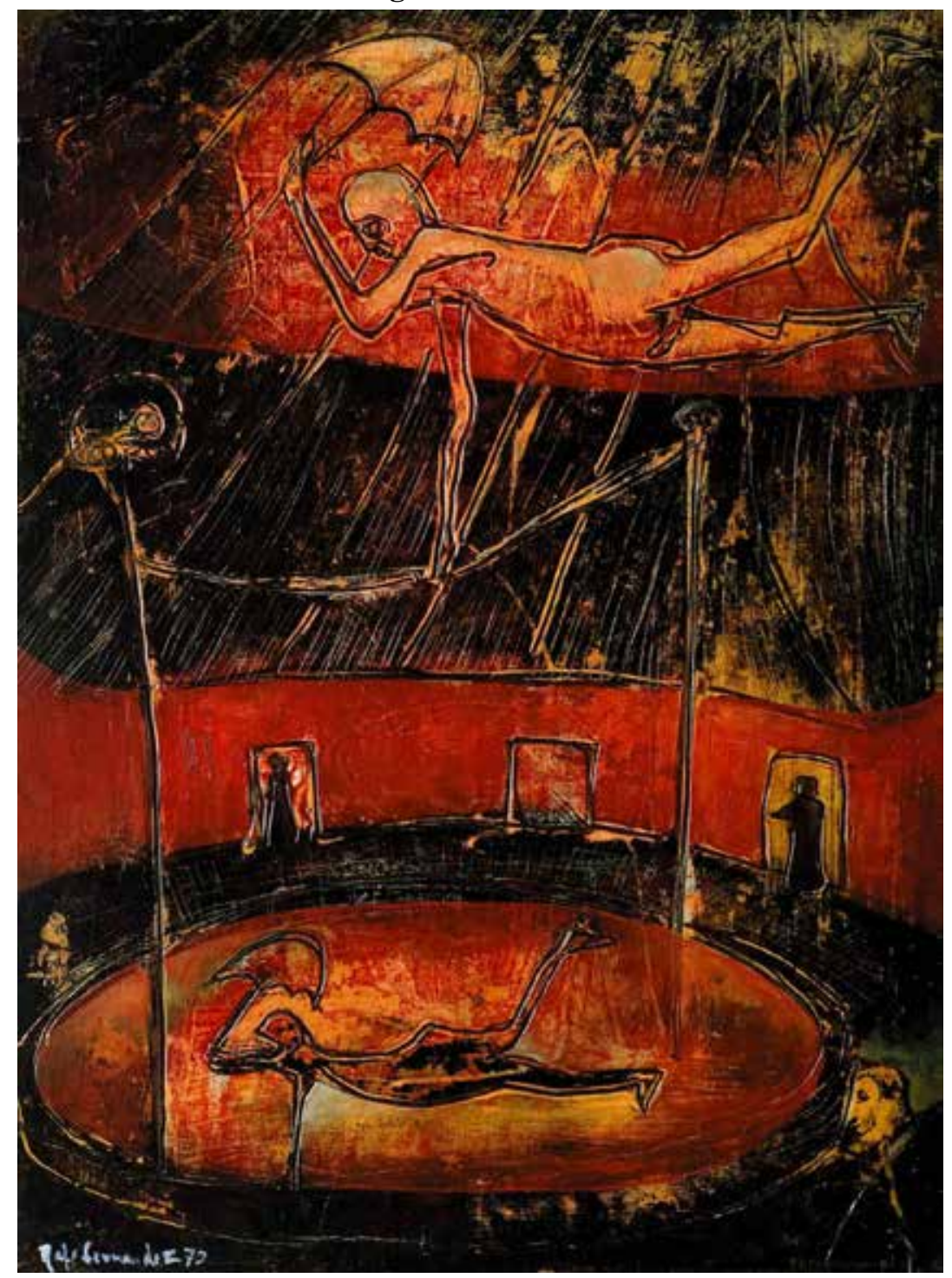

Fuente: Alma Fernández Tercero 
Figura 10. Algo por acontecer

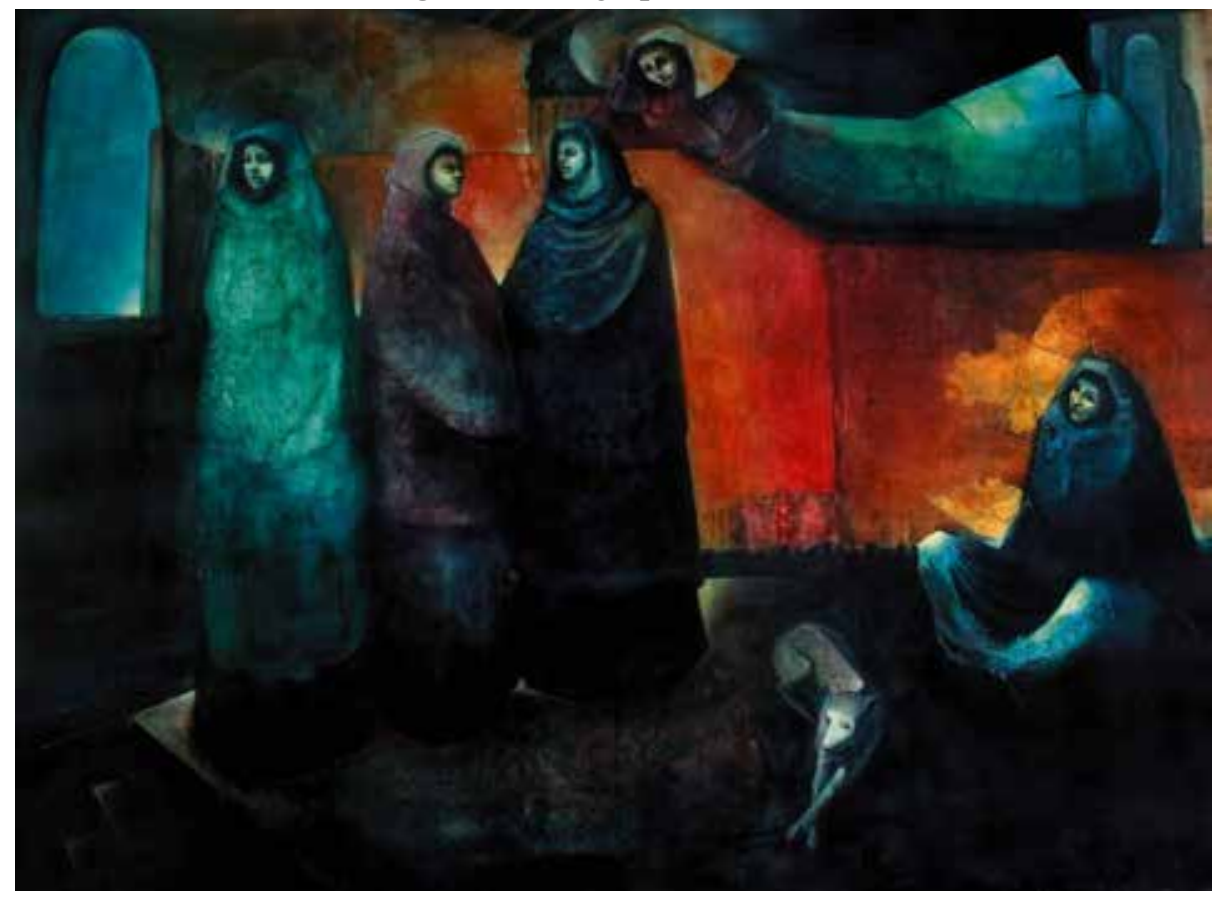

Fuente: Alma Fernández Tercero

Los años ' 80 vienen a él con la rotunda decisión de dedicarse por completo a su pintura, asumiendo todos los riesgos. A partir de esta audaz y valiente apuesta, toda su energía se enfoca en su obra al llevar a tope el potencial productivo que determina el eje, que desde entonces, quedaría grabado en la memoria colectiva: las mujeres de Rafa Fernández. Esta es la imagen femenina que él mismo definía como un elemento vital, creación en sí misma, reproducción, naturaleza de la que partía toda necesidad biológica de la vida que para él era la pintura. 
Figura 11. La bañista

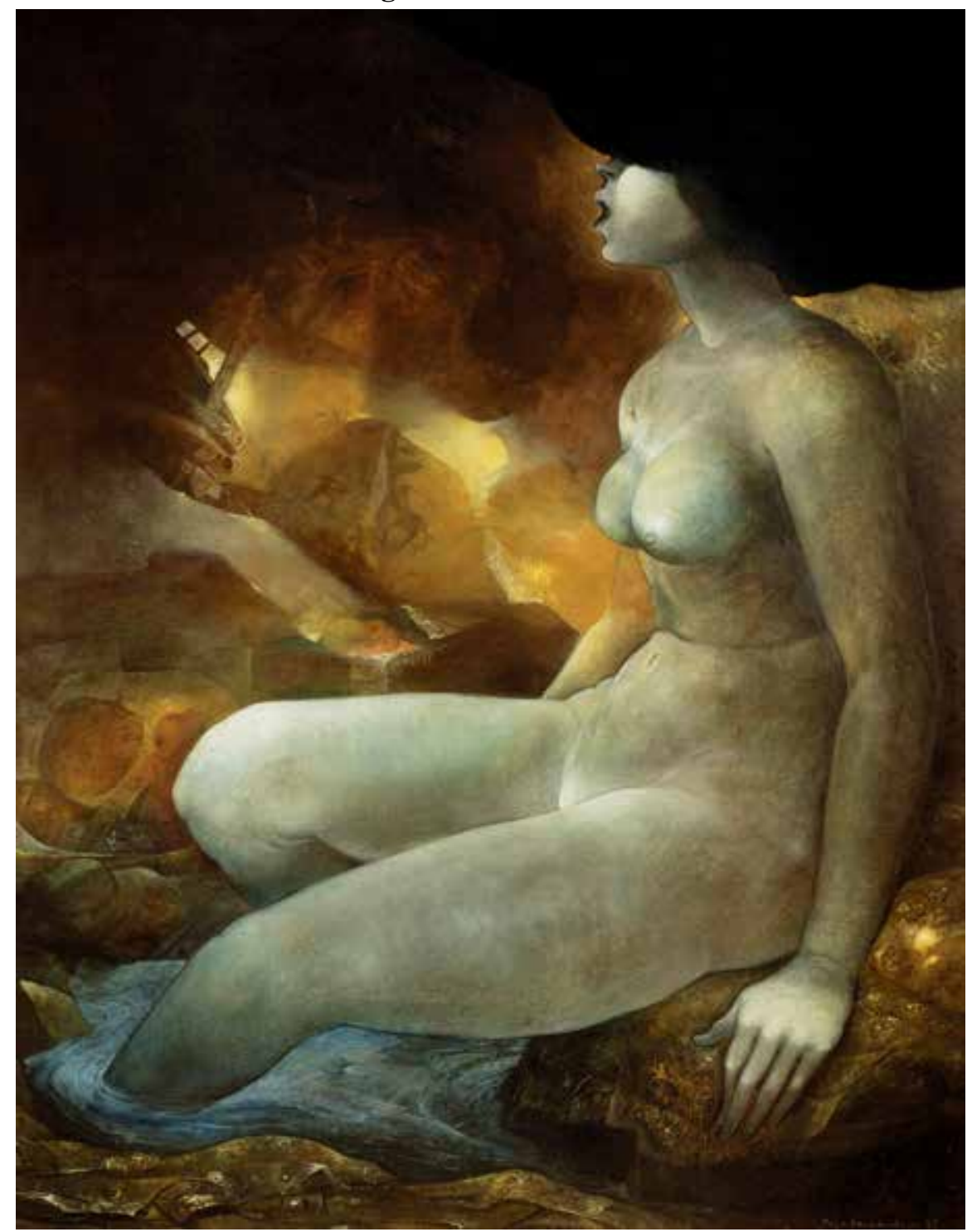

Fuente: Alma Fernández Tercero 
Galería en tributo al pintor costarricense Rafa Fernández (1935-2018)

Figura 12. La dama del Alba

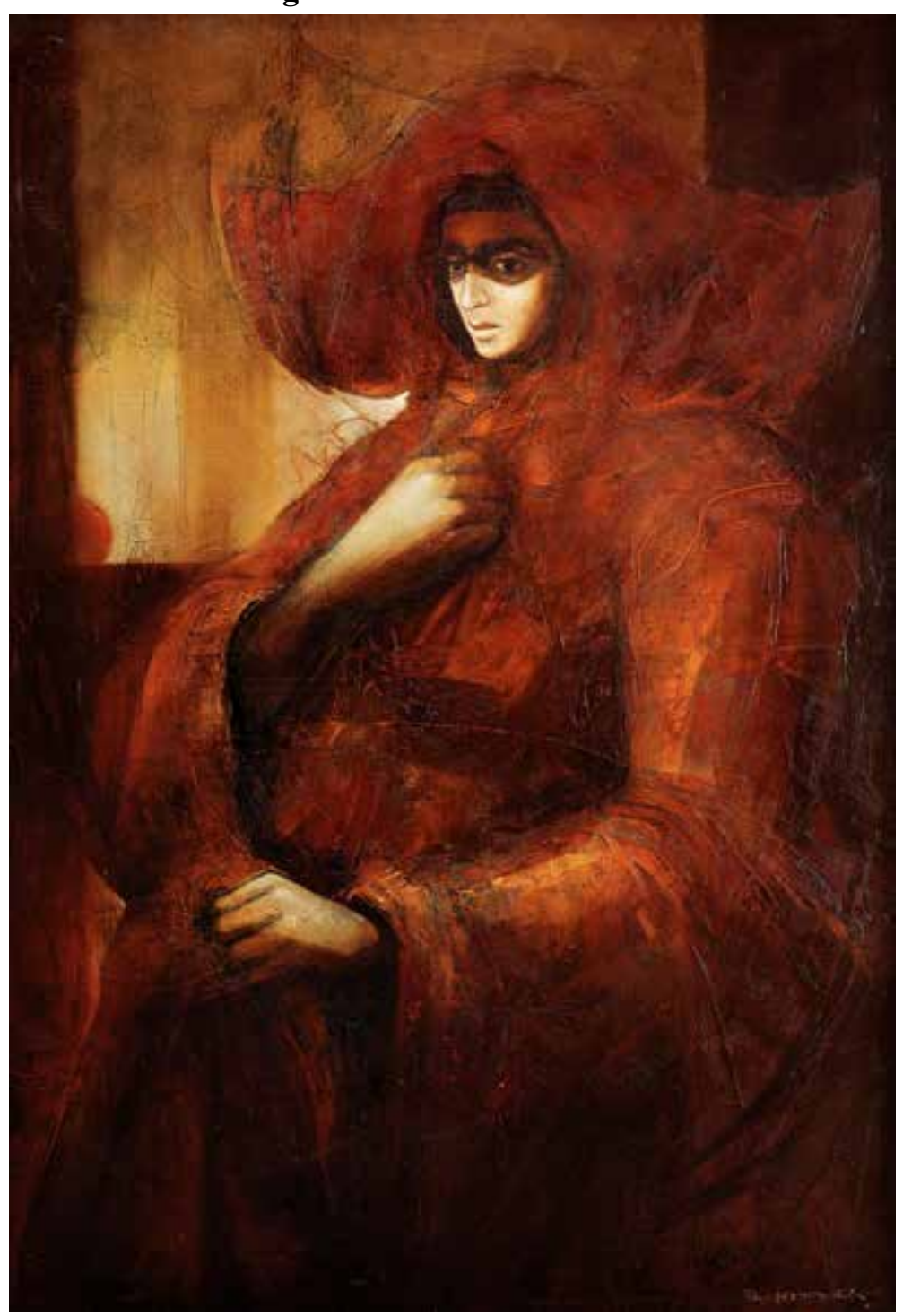

Fuente: Alma Fernández Tercero 
Figura 13. La nona

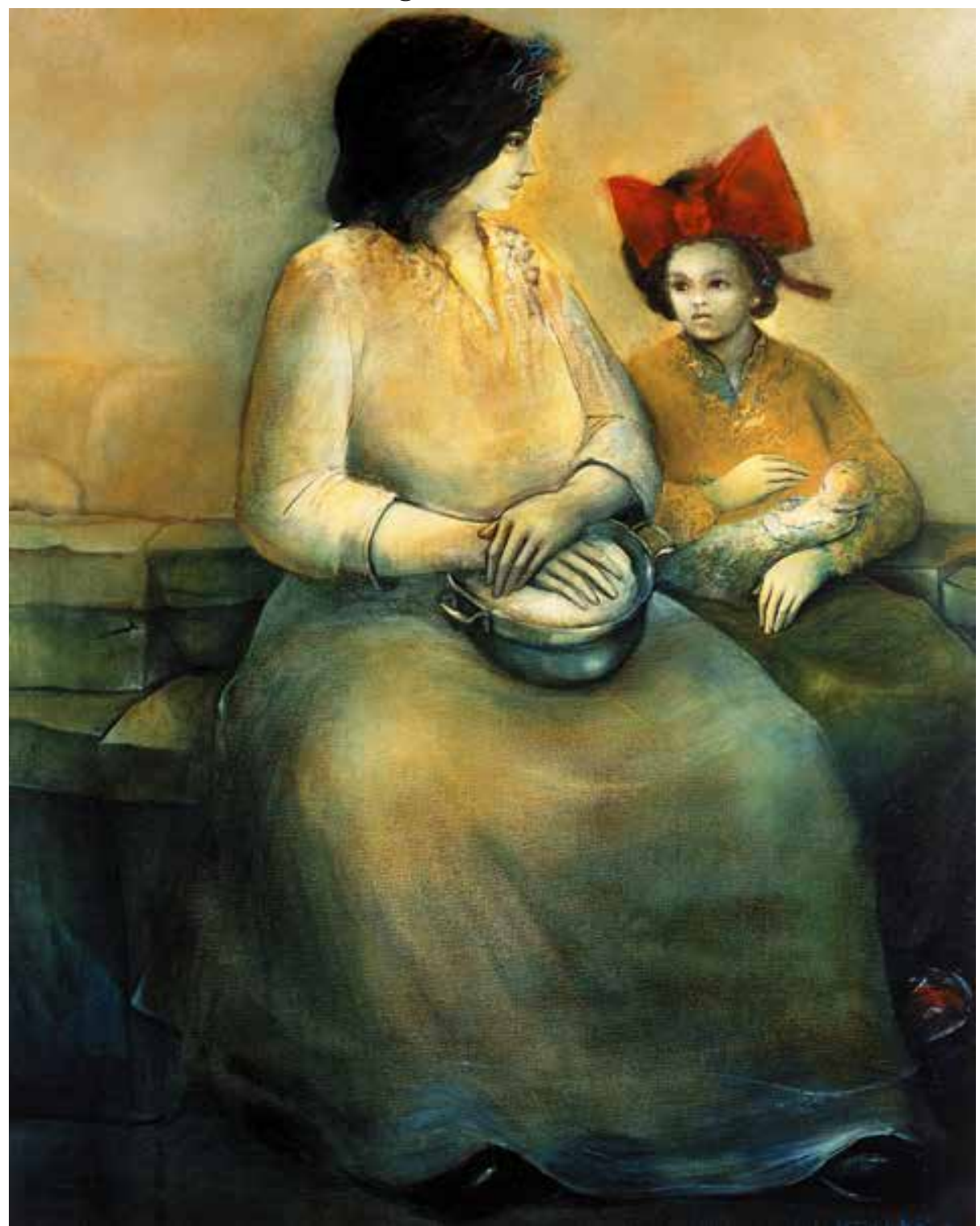

Fuente: Alma Fernández Tercero

En la década del '90, después de un lustro de vivir en Madrid, su universo creativo se ha expandido, sus mujeres se enaltecen, su nivel técnico alcanza la maestría y recibe en Madrid premios y reconocimientos que impulsan su carrera. 
Figura 14. Mujer con bodegón

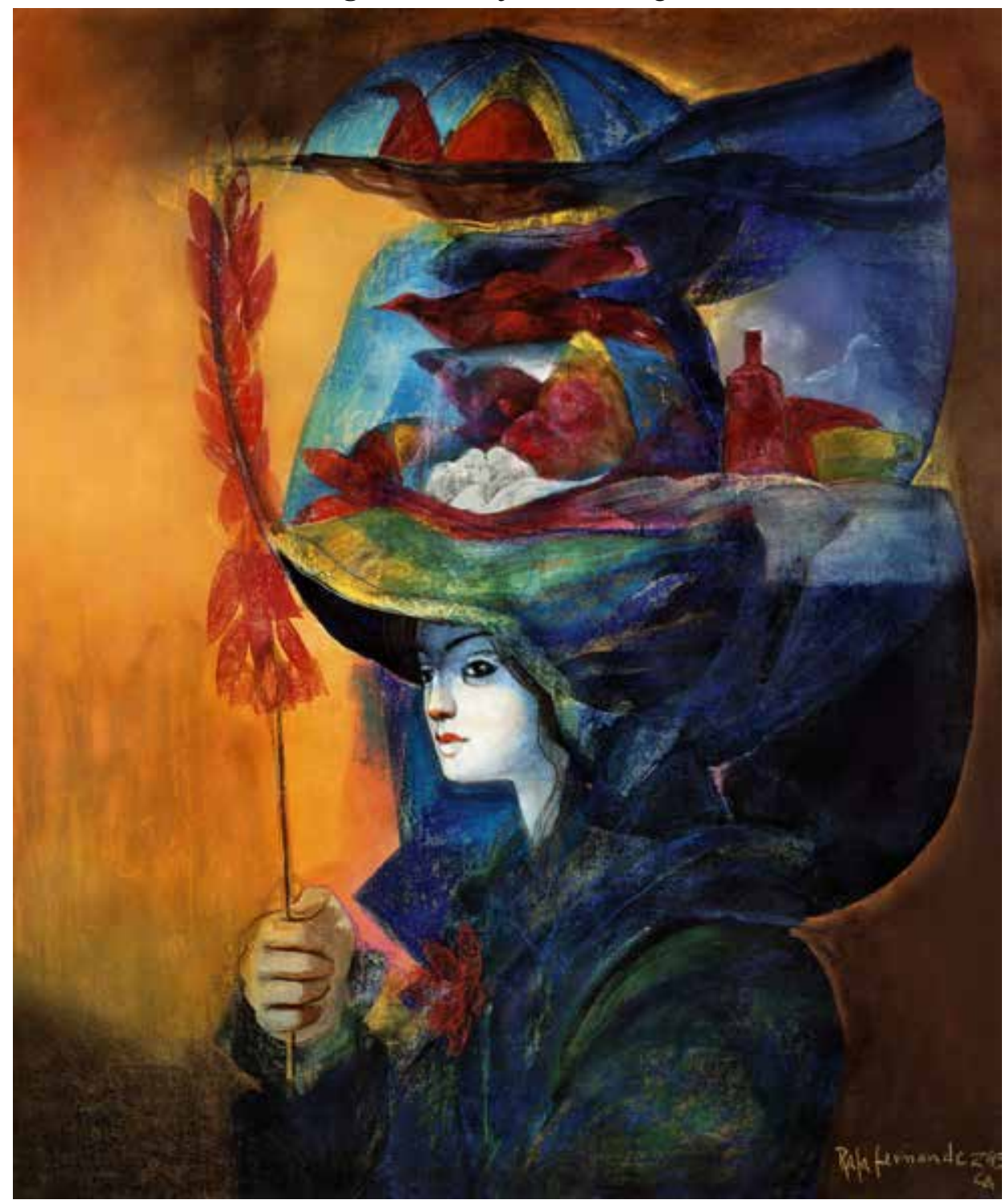

Fuente: Alma Fernández Tercero 
Figura 15. El abanico

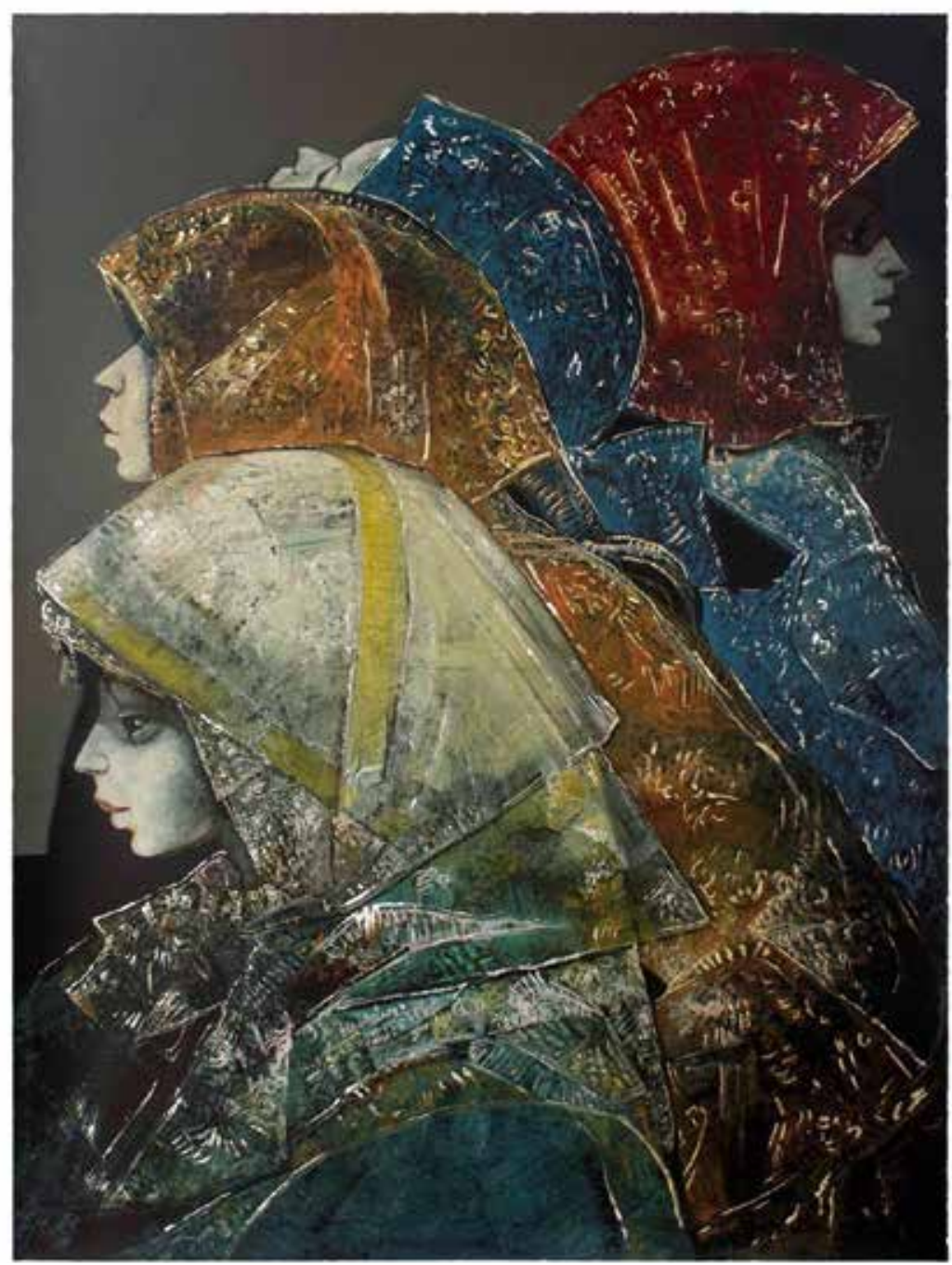

Fuente: Alma Fernández Tercero 
Figura 16. Concierto

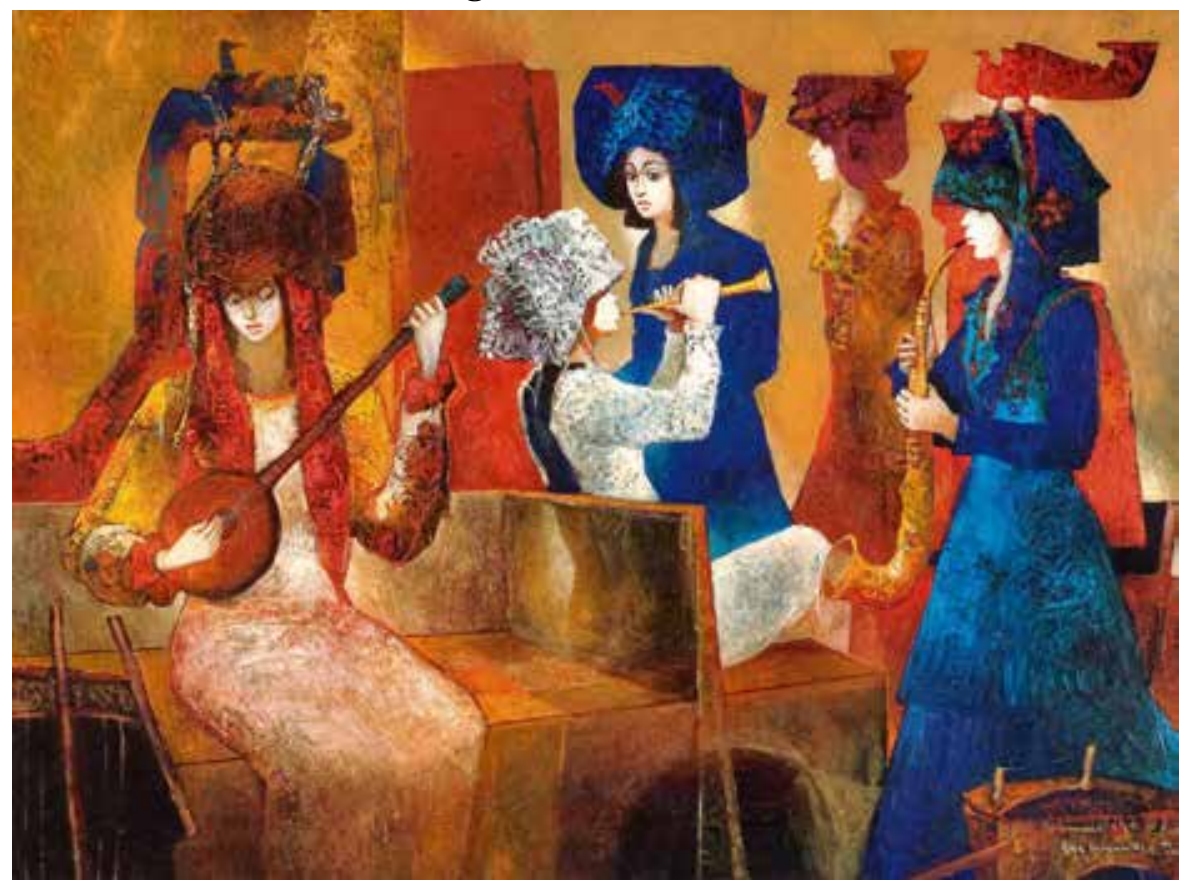

Fuente: Alma Fernández Tercero

Así transcurren los últimos años del siglo XX para él; exposiciones, viajes, reconocimientos, hasta que en el 2002 un terrible acontecimiento lo cambia todo, un huracán llega como un zarpazo en dos derrames cerebrales que por poco le arrancan la vida, pero vuelve a la arena con más fuerza que nunca y dándole un giro a la trampa, se reinventa, se libera y vuelve a pintar con la absoluta entrega de su alma. 
Figura 17. Violinista de la luna

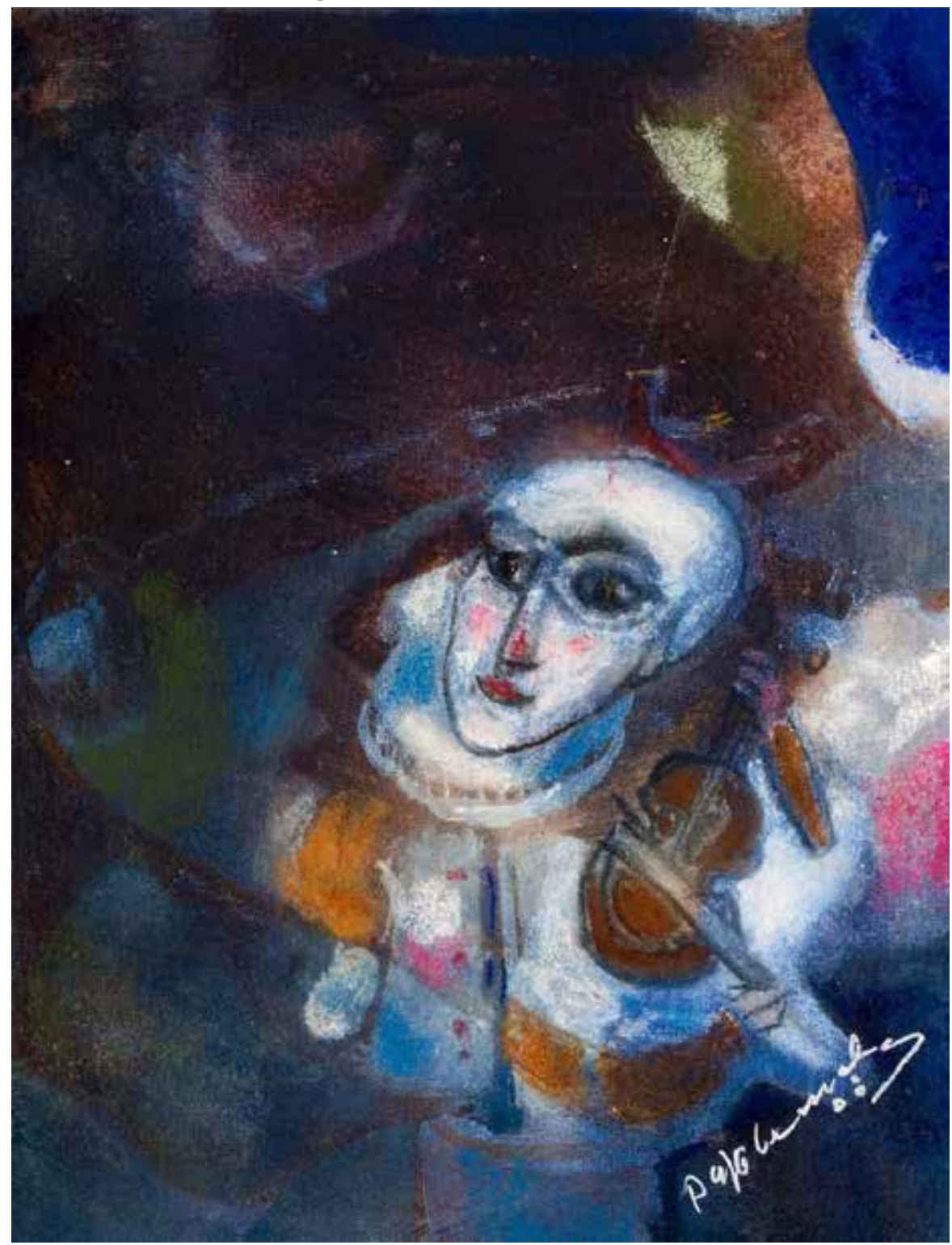

Fuente: Alma Fernández Tercero 
Galería en tributo al pintor costaricense Rafa Fernández (1935-2018)

Figura 18. Tarde malva en la terraza

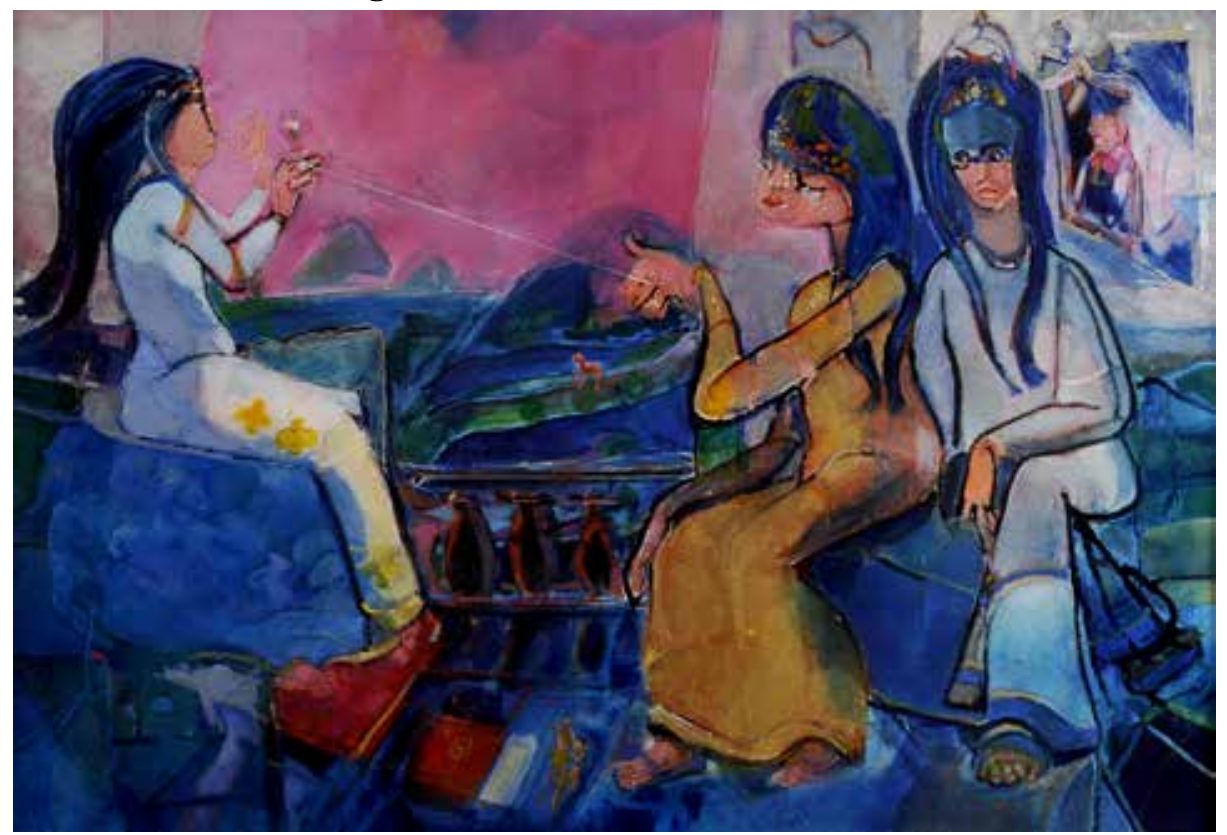

Fuente: Alma Fernández Tercero 
Figura 19. Piel adentro

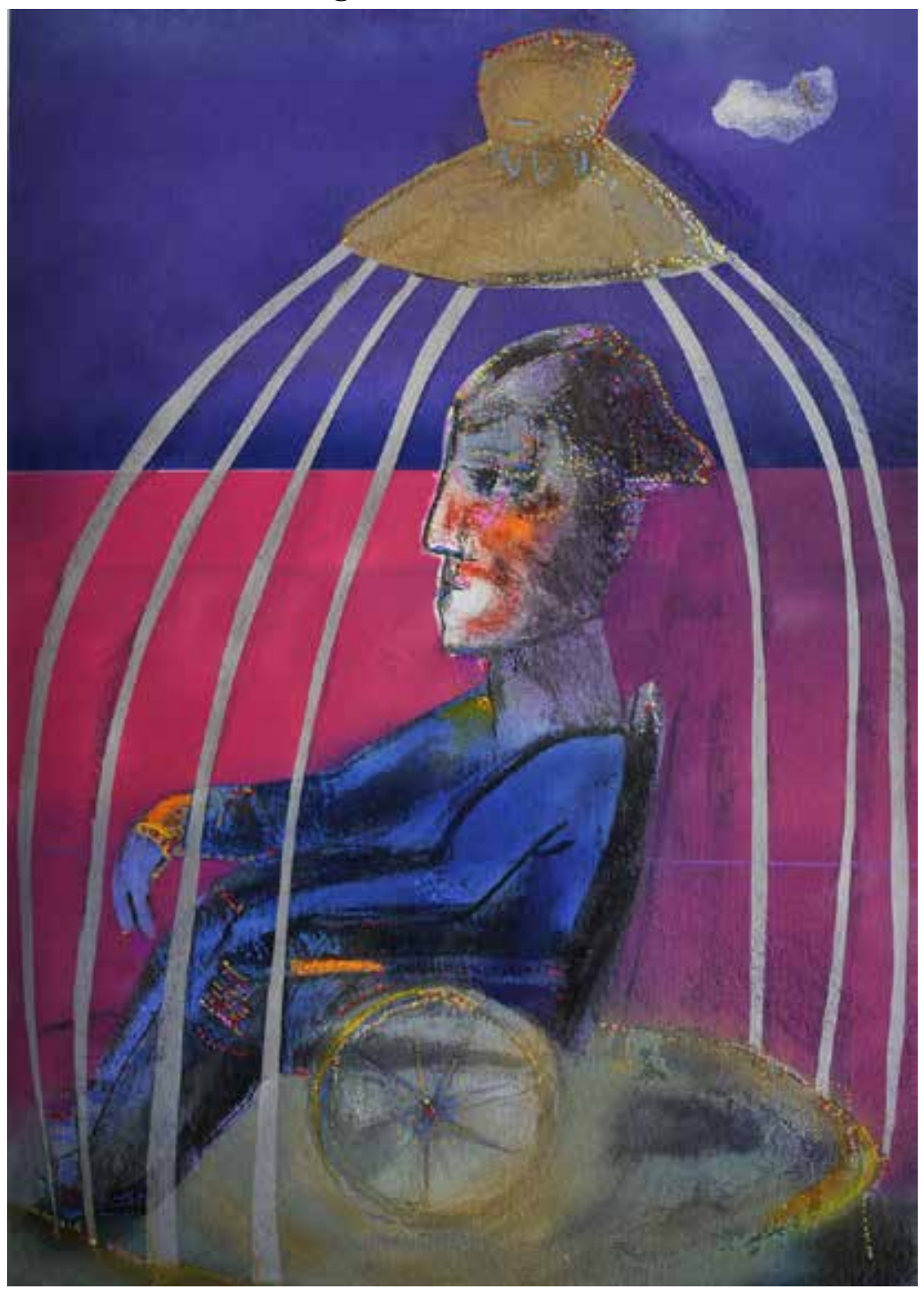

Fuente: Alma Fernández Tercero

Es esta la etapa en la que, a través de todos los brillos, de todas las luces y de todos los colores, conozco a fondo a mi padre y entiendo los significados de esta obra en la que él habita y a través de la cual se comunica, prueba de ello es la frase que me regaló hace un tiempo, en la que él mismo lo explica: "Mientras más tenue se hace mi voz, más fuerte se hace mi pintura". 
Figura 20. Un buen día del pirata

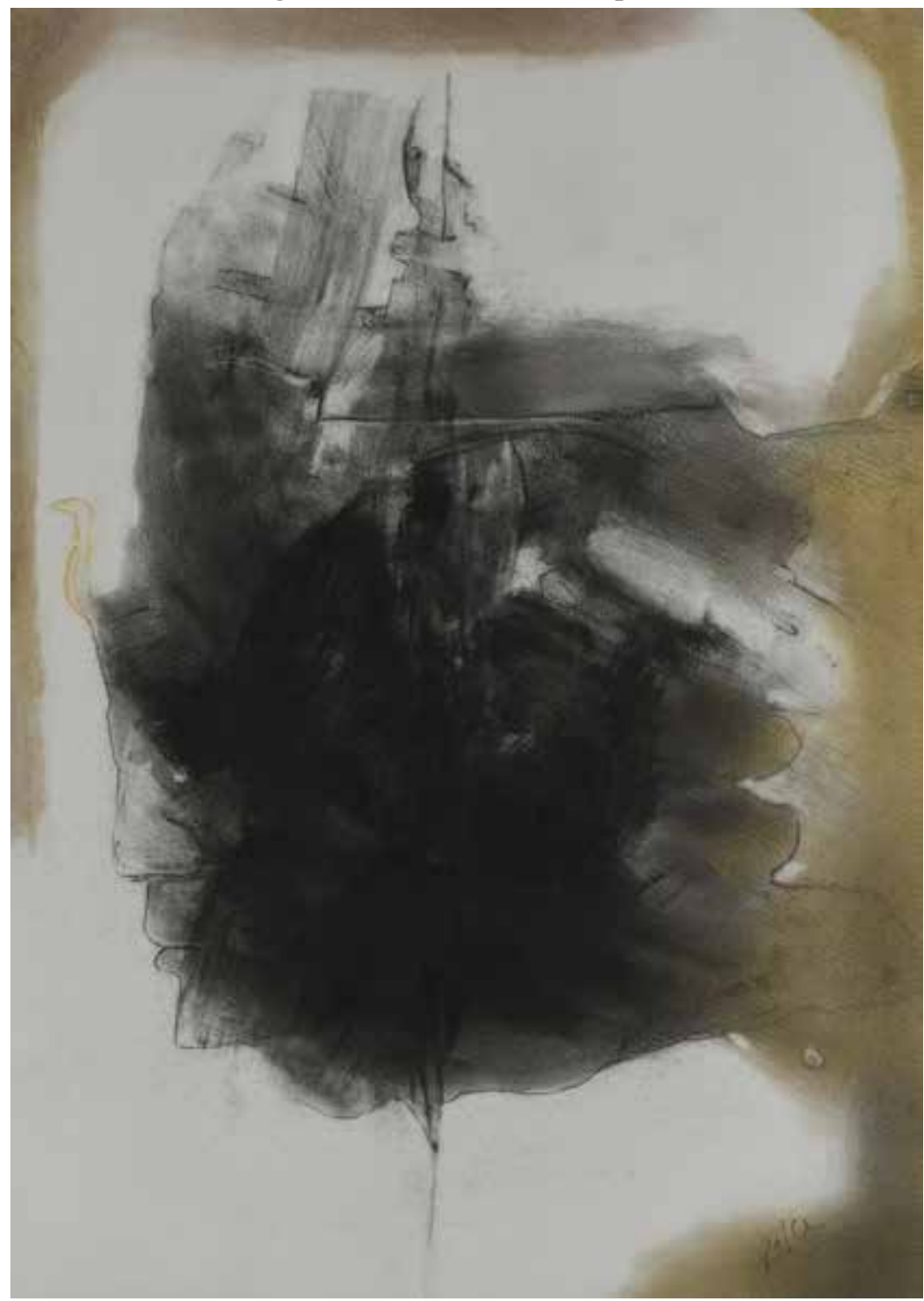

Fuente: Alma Fernández Tercero

Yo habito mi pintura, me dijo mi padre hace unos años, pero es hasta ahora que entiendo el alcance de aquella frase, porque no se refería solo a que estaba en el azul del que se adueñó o en las miradas vivas de sus personajes, o en la profundidad de sus atmósferas, sino que se refería a la comunión sacramental entre él y su pintura. 
Figura 21. Viajero del tiempo

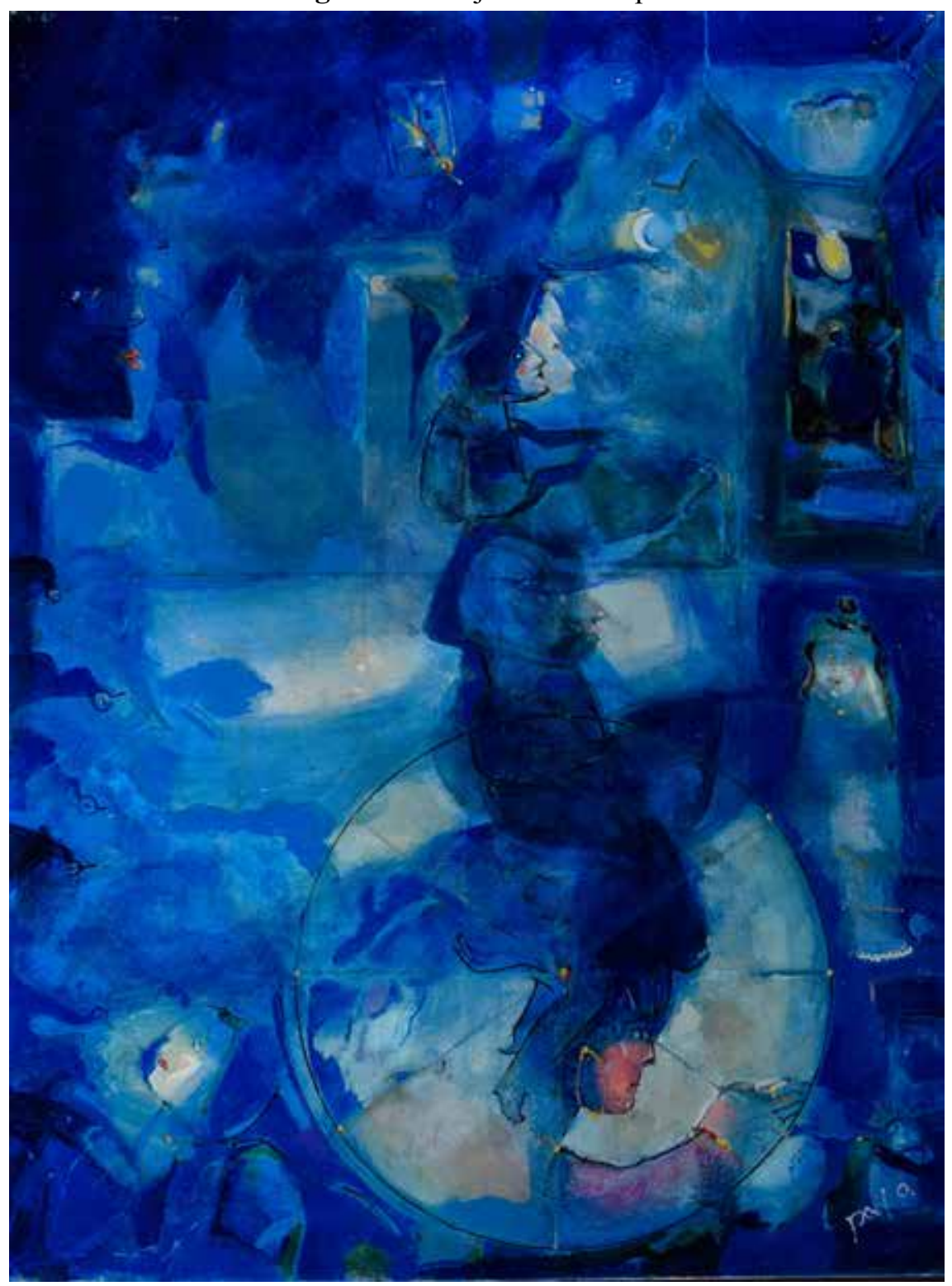

Fuente: Alma Fernández Tercero

Nunca paró de pintar, nunca dejó de crear, ni siquiera cuando su cuerpo se negaba a obedecer su voluntad, porque fue entonces cuando más pintó. Yo sabía que cuando mi papá partiera, su obra iba a alcanzar toda su dimensión pero no pensé que a mí misma me sorprendería descubrirla. 
En la elaboración del inventario que he estado realizando después de su muerte, he descubierto una obra nueva a pesar de que ya la conocía. Esto ocurre porque la mirada cambia, porque cada una de sus obras es ahora su última obra, porque cada una de esas obras es parte integral de un único cuadro que pintó a través de toda su vida, es aquí donde se define el concepto de obra total, y su firma, Rafa Fernández, es la huella indeleble que quedará impresa en la historia del arte latinoamericano. 